
\title{
¿ Research Square \\ In vitro and in vivo antitrypanosomal activities of Echinops kebericho root extract
}

\section{Debela Abdeta}

School of Veterinary Medicine, Wollega University

\section{Nigatu Kebede}

Aklilu Lemma Institute of Pathobiology, Addis Ababa University

\section{Mirutse Giday}

Aklilu Lemma Institute of Pathobiology, Addis Ababa University

\section{Getachew Terefe}

Department of Veterinary Parasitology, Addis Ababa University

Solomon Mequanente Abay ( $\sim$ solomonabay@gmail.com )

https://orcid.org/0000-0002-7844-3771

\section{Research note}

Keywords: Trypanosomiasis, Trypanosoma congolense, Echinops kebericho

Posted Date: September 5th, 2019

DOI: https://doi.org/10.21203/rs.2.13929/v1

License: (c) (1) This work is licensed under a Creative Commons Attribution 4.0 International License. Read Full License 


\section{Abstract}

Objective: Microbial resistance to the few conventional antitrypanosomal drugs, increasing resistance of vectors to insecticides, lack of effective vaccines and adverse effects of the existing antitrypanosomal drugs justifies the urgent need for effective, tolerable and affordable drugs. We assessed antitrypanosomal effect of hydromethanolic extract of Echinops kebericho Mesfin roots against Trypanosoma congolense field isolate using in vitro and in vivo techniques. Parasite load, packed cell volume (PCV), body weight and rectal temperature in Swiss albino mice were assessed. This finding is part of the outcomes of drug discovery research for neglected tropical diseases. Result: The extract ceased motility of the trypanosomes within $40 \mathrm{~min}$ at 4 and $2 \mathrm{mg} / \mathrm{ml}$ concentration whereas in the untreated control motility continued for more than $160 \mathrm{~min}$. The extract also reduced parasitemia, prevented drop in PCV and body weight significantly $(\mathrm{p}<0.05)$, as compared to control. Phytochemical analysis showed the presence of flavonoids, triterpines, steroids, saponins, glycosides, tannins and alkaloids. It is observed that this extract has activity against the parasite. Isolation and purification of specific compounds are required to identify hit compounds responsible for the antitrypanosomal activity of the studied medicinal plant.

\section{Introduction}

Current trypanosomiasis control relies on trypanocidal drugs, use of trypanotolerant cattle breeds and control of the tsetse fly vector. The major strategy to control trypanosomiasis relied on the use of trypanocidal drugs, which is challenged by an increasing problem of resistance [1]. The search for new chemical entities that are effective against trypanosomes, safe and affordable for disease-endemic countries is rational to fight against the trypanosomiasis [2]. To this effect, exploring natural products and synthetic sources are required to feed the pipeline of drug developments for trypanosomiasis control and elimination.

Plants are potential sources of new drugs due to the presence of countless number of secondary molecules that have pharmacological effects [3]. Exploring traditionally claimed medicinal plant for the biological activity gave humankind a number of antiprotozoal medications.

Validation of medicinal plant for their antitrypanomal activity will guide the society for the best approach to employ their indigenous knowledge and at the same time provide hit compounds to feed future pipeline for antitrypanomal drug development. Echinops kebericho (Mesfin), [Amharic vernacular name: kebericho], belongs to family Asteraceae/Compositeae, endemic to Ethiopia, is erect perennial herb or shrub [4]. Its varied medicinal applications are documented in the ancient medico-religious pharmacopoeia, and are well-recognized by modern-day traditional professionals/specialists [5].

Echinops kebericho root is used for the treatment of animal trypanosomiasis in Ethiopia [6]. However, there is no laboratory-based evidence for the effectiveness and safety of this plant. The objective of this study was, therefore, to assess the in vitro and in vivo antitrypanosomal effects of hydromethanolic 
extract of E. kebericho roots using field isolate of $T$. congolense, which is the most important cause of domestic animal trypanosomiasis [7]. Experimental mice infection model has been selected given the provision of this model new insight in both human and animal trypanosomiasis [8].

\section{Method}

\section{Plant collection and authentication}

Roots of E. kebericho were collected in November 2015 in Jimma Arjo Woreda of Eastern Wollega, Ethiopia. Leaves with flower specimen of the plant were identified and authenticated at Aklilu Lema Institute of Pathobiology (ALIPB), and the vouchers were deposited at the National Herbarium of Addis Ababa University with number DA 01.

\section{Preparation of plant extracts}

Air dried powdered plant material was macerated in an Erlenmeyer flask with $80 \%$ methanol at room temperature for a period of 72 hours. It was then filtered with gauze followed by Whatman filter paper (No.1). The residue was re-macerated once again to increase the yield. The filtrate was concentrated using rotary evaporator to remove methanol. Then the concentrated filtrate was lyophilized to remove water.

\section{Test organism and experimental animals}

Trypanosoma congolense was obtained from Department of Veterinary Parasitology, Addis Ababa University by infecting Swiss albino mice via intraperitoneal inoculation.

Swiss albino mice of either sex, weighing 30-35 g (age 10-12 weeks) were purchased from Ambo University (Ethiopia). They were fed with standard pellet and provided water ad libitum; maintained at room temperature of $23-25^{\circ} \mathrm{C}$ with relative humidity of $60-65 \%$. The care and handling of animals were in accordance with internationally accepted guidelines for use of animals [9].

\section{Experimental procedures}

\section{Evaluation of in vitro antitrypanosomal activity}

In vitro test was performed in triplicates to detect any motile trypanosomes in a 96 well microplate. Twenty microliter of blood containing about 16-32 organisms per field were mixed with $5 \mu \mathrm{L}$ of the test substance at concentrations of $2.5,5,10,20 \mathrm{mg} / \mathrm{mL}$ to produce test concentrations of $0.5,1,2,4.0$ $\mathrm{mg} / \mathrm{mL}$, respectively.

Phosphate buffer saline ( $\mathrm{pH} \mathrm{7.2)} \mathrm{and} \mathrm{standard} \mathrm{trypanocidal} \mathrm{drug,} \mathrm{diminazene} \mathrm{aceturate} \mathrm{(DA)} \mathrm{were} \mathrm{used}$ to serve as untreated control and treated controls, respectively. The mixtures were incubated at $37^{\circ} \mathrm{C}$ for up to $3 \mathrm{~h}$. During the period, motility of the parasites was checked in 20 min interval under microscopy 
(X40 objective lens). Briefly, about $2 \mu \mathrm{L}$ of test mixtures was placed microscope slide and covered with cover slips and the parasites observed for reduced motility or complete cessation of motility.

\section{Evaluation of in vivo antitrypanosomal activity}

Thirty mice of either sex were randomly grouped into five (I- V) groups of 6 animals per group. They were intraperitoneally infected with $0.2 \mathrm{~mL}$ of $T$. congolense $\left(5^{\star} 10^{5}\right.$ parasites $\left./ \mathrm{mL}\right)$ suspension. Groups I and II were administered $0.3 \mathrm{~mL}$ distilled water per orally and DA $(3.35 \mathrm{mg} / \mathrm{kg})$ per orally respectively to serve as untreated and treated controls, while groups III, IV, and V were administered with the extract at daily doses of 100,200 and $400 \mathrm{mg} / \mathrm{kg}$ body weight respectively for 7 consecutive days per orally from $10^{\text {th }}$ days of parasite inoculation. Parasitemia and packed cell volume (PCV) were observed every 4 days for 21 days while body weight and rectal temperature was monitored every 2 days [10].

\section{Determination of parasitemia}

On the tenth day post infection and every four days, the parasitemia level of mice was checked.

Parasitemia was monitored by examining blood drawn from the tail of mice under microscopy at $\times 400$ magnifications using the "Rapid Matching" method of Herbert and Lumsden [11]. Monitoring of parasitemia was performed every four days until the $21^{\text {th }}$ day post-treatment initiation $[12,13]$.

\section{Determination of packed cell volume}

PCV was determined using microhematocrit centrifuge and microhematocrit tube reader. PCV was monitored on day of treatment initiation and every 4 days until $21^{\text {th }}$ day post treatment initiation $[14,15]$.

\section{Determination of body weight}

Body weight of experimental animals were recorded on the day of parasite challenge, day of treatment initiation and every other day for 21 days [16].

\section{Determination of rectal temperature}

Rectal temperature was measured using digital rectal thermometer (Mettler Toledo, Switzerland) on the day of parasite inoculation, day of treatment commencement and every other day thereafter for 21 days [14].

\section{Phytochemical screening for secondary metabolites}

Standard screening tests of the extract was carried out for secondary metabolites according to the methods described in the literature [17-22].

\section{Statistical analysis}


Data were presented as mean \pm SEM and analyzed using Statistical Package for Social Science version 20. Analysis of variance was employed to test statistical difference within all groups followed by Tukey test for significance test between two groups. $P$ values less than 0.05 were considered statistically significant.

\section{Results}

\section{Experimental animals follow up}

Parasite load, body temperature and weight of animals were recorded. When the parasite load increased and confirmed that experimental animals could not survive due to infection, inhalation anesthetic in a transparent euthanasia chamber was used for humane euthanasia of experimental animals. Data set collected from solvent control and low dose extract treated groups were only for few days (Figure 1 and 2) due to rapid increment of parasite load.

\section{In vitro antitrypanosomal activity}

Hydromethanol extract of E. kebericho roots ceased motility of the trypanosomes within 40 min at 4 and $2 \mathrm{mg} / \mathrm{ml}$ concentration. At $0.5 \mathrm{mg} / \mathrm{ml}$ of hydromethanol extract of E. kebericho root, the motility was maintained for $80 \mathrm{~min}$ after which motility of the parasite is completely ceased. The motility of parasites ceased at 60 minutes for $E$. kebericho roots extract at dose of $1 \mathrm{mg} / \mathrm{ml}$ (Table 1).

Table 1: In vitro activity of hydromethanolic extract of E. Kebericho roots

\begin{tabular}{|c|c|c|c|c|c|c|}
\hline \multirow{2}{*}{$\begin{array}{l}\text { Duration } \\
\text { (min) }\end{array}$} & \multicolumn{4}{|c|}{ E. kebericho extract (Motility) } & \multirow{2}{*}{$\begin{array}{l}\text { DA 3.35mg/ml } \\
\text { (Motility) }\end{array}$} & \multirow{2}{*}{$\begin{array}{l}\text { Control } \\
\text { (Motility) }\end{array}$} \\
\hline & $\begin{array}{l}0.5 \\
\mathrm{mg} / \mathrm{ml}\end{array}$ & $\begin{array}{l}1 \\
\mathrm{mg} / \mathrm{ml}\end{array}$ & $\begin{array}{l}2 \\
\mathrm{mg} / \mathrm{ml}\end{array}$ & $\begin{array}{l}4 \\
\mathrm{mg} / \mathrm{ml}\end{array}$ & & \\
\hline 0 & + & + & + & + & + & + \\
\hline 20 & + & + & + & + & - & + \\
\hline 40 & + & + & - & - & - & + \\
\hline 60 & + & + & - & - & - & + \\
\hline 80 & + & - & - & - & - & + \\
\hline 100 & - & - & - & - & - & + \\
\hline 120 & - & - & - & - & - & + \\
\hline 140 & - & - & - & - & - & + \\
\hline 160 & - & - & - & - & - & + \\
\hline 180 & - & - & - & - & - & - \\
\hline 200 & - & - & - & - & - & - \\
\hline
\end{tabular}

\section{Effect on parasitemia of $T$. congolense infected mice}

Parasitemia level was assessed at day 4 post-treatment in all thirty experimental animals randomly assigned to different groups (30/30). All doses of the extract including the standard drug suppressed 
parasitemia at day 4 post-treatment $(\mathrm{p}<0.05)$. Treatment with extract at $200 \mathrm{mg} / \mathrm{kg}$ and $400 \mathrm{mg} / \mathrm{kg}$ and DA3.35mg/kg showed statistically significant $(p<0.05)$ reduction in parasitemia on day 8 to day 12 posttreatments compared to $100 \mathrm{mg} / \mathrm{kg}$ body weight (Figure $1-\mathrm{A}$ ).

\section{Effect on packed cell volume of $T$. congolense infected mice}

While the mean PCV in the untreated control group continued to decrease until all the animals died due to infection, $200 \mathrm{mg} / \mathrm{kg}$ and $400 \mathrm{mg} / \mathrm{kg}$ of the extract and DA $3.35 \mathrm{mg} / \mathrm{kg}$ shows an increase in mean PCV values from day 0 to day 12 post-treatment while treatment. PCV measurement in blood of infected mice treated with E. kebericho at dose of $200 \mathrm{mg} / \mathrm{kg}$ and $400 \mathrm{mg} / \mathrm{kg}$ and DA $3.35 \mathrm{mg} / \mathrm{kg}$ showed statistically significant $(p<0.05)$ improvement compared with those untreated control on day 4 post treatment initiation (Figure 1-B).

\section{Effect on body weight of $T$. congolense infected mice}

There is statistically significant $(p<0.05)$ body weight changes in $200 \mathrm{mg} / \mathrm{kg}, 400 \mathrm{mg} / \mathrm{kg}$ and DA $3.35 \mathrm{mg} / \mathrm{kg}$ treated groups compared with $100 \mathrm{mg} / \mathrm{kg}$ through day 4 to day 6 post-treatment initiation and with untreated control on day 4 post-treatment (Figure 2-A).

\section{Effects on rectal temperature of $T$. congolense infected mice}

The rectal temperatures of the animals were fluctuating throughout the experiment. There is no observed difference throughout the follow up period (Figure 2-B).

\section{Phytochemical screening}

Phytochemical screening revealed the presence of saponins, tannins, phenol, terpenes, flavonoids, glycosides and alkaloids.

\section{Discussion}

In the present study, antitrypanosomal activities of the E. kebericho roots suggested that the extract could contain trypanocidal constituents that are active in the in vitro and in vivo environments. Parasites motility constitutes a relatively reliable indicator of viability of most trypanosomes [23] and a complete elimination or reduction in motility of trypanosomes when compared to the control could be taken as index of trypanocidal activity [24].

In vivo assessment of the extract revealed a marked suppression of parasite load at 200 and $400 \mathrm{mg} / \mathrm{kg}$ compared to group treated with vehicle control even though the extract failed to clear the parasite. Further investigation is required to see whether the extract will have an improved effect or not when administered by injection to minimize the negative impact of limited bioavailability from the gut.

The mean PCV in the untreated control group continued to decrease until all the animals in the group died due to infection while in treated groups the value shows normal range. The decrease in PCV value for 
untreated control may be due to anemia which is the most outstanding clinical and laboratory feature of African trypanosomiasis [25].

The present study showed that the E. kebericho extract contain secondary metabolites: saponins, tannins, phenol, terpenes, flavonoids, glycosides and alkaloids. The responsible active components were yet to be isolated. Previous studies showed that flavonoids are effective antitrypanosomal substances against different trypanosome species [26]. Phenolics and polyphenols have also been reported to have antitrypanosomal activity by inhibiting the trypanosome alternative oxidase [27]. Alkaloids affect trypanosomes by DNA intercalation in combination with the inhibition of protein synthesis [26]. The in vitro and in vivo activities of the E. kebericho extract in the present study might be contributed by multiple secondary metabolites.

The present study also demonstrated that the extract is safe and tolerable since no treatment-related signs of toxicity were noticed in the animals throughout the observation period. Per oral administration of the hydromethanolic extract of $E$. kebericho root extract produced neither significant toxic signs nor death during the observation period of 14 days after a single administration of $2000 \mathrm{mg} / \mathrm{kg}$ with oral median lethal dose greater than $2000 \mathrm{mg} / \mathrm{kg}$ in mice. Another study showed that the hydroethanolic extract of $E$. kebericho root (up to a dose of $5,000 \mathrm{mg} / \mathrm{kg}$ ) did not produce sign of toxicity [28].

In conclusion the present study provides evidence to the antitrypanosomal activity of hydromethanolic extract of E. kebericho root and validates the traditional practice of Ethiopian community to control trypanosomiasis. Further in vitro and in vivo activities of the extract on other species of trypanosome are recommended. In addition, the responsible compound (s) for activity shall be characterized to identify hits and develop lead compounds.

\section{Limitation of the study}

The main limitation is that the screening was conducted using one type parasite isolates, and therefore extrapolating the result to all Trypanosoma species is unjustified.

\section{List Of Abbreviations}

PCV Packed cell volume

ALIPB Aklilu Lema Institute of Pathobiology

DA Diminazene aceturate

OECD Economic Co-operation and Development

\section{Declarations}

\section{Ethics approval}


All applicable international, national, and/or institutional guidelines for the care and use of animals were followed. Ethical approval for the conduct of the research project was obtained from the Scientific and Ethics Committee of the Department of Pharmacology, School of Medicine, Addis Ababa University.

\section{Availability of data and materials}

Data will be available up on request.

\section{Funding}

Addis Ababa University supported this research work as part of postgraduate education. The funding body had no role in the design of the study, the collection, analysis and interpretation of data, or in writing the manuscript.

\section{Acknowledgements}

Authors would like to thank ALIPB technicians for their unreserved technical support.

\section{Consent for publication}

Not applicable.

\section{Competing interests}

The author(s) declare that they have no competing interests.

\section{Author's contributions}

DA participated in the study design, carried out the experiments, performed the statistical analysis, and drafted the manuscript; MG, NK, GT and SMA participated in the study design and the execution of the experiments; SMA contributed to the revision of the manuscript; MG, NK, GT and SMA critically revised the manuscript. All authors read and approved the final manuscript.

\section{Competing interests}

The authors declare that they have no competing interests.

\section{References}

1. Connor RJ. The diagnosis, treatment and prevention of animal trypanosomiasis under field conditions [Internet]. FAO. 1992 [cited 2018 Dec 10]. Available from: http://www.fao.org/docrep/004/T0599E/T0599E01.htm

2. Fromsa A, Mulaw S, Addis M. Study on the prevalence of major trypanosomes affecting bovine in tsetse infested Asosa district of Benishangul Gumuz regional state, Western Ethiopia. Glob Vet. 2011;7:330-6. 
3. Newman D, Cragg G, Snader K. Natural products as sources of new drugs over the period 1981-2002. J Nat Prod. 2003;66:1022-37.

4. Belay G, Tariku Y, Kebede T, Hymete A, Mekonnen Y. Ethnopharmacological investigations of essential oils isolated from five Ethiopian medicinal plants against eleven pathogenic bacterial strains. Phytopharmacol. 2011;1:133-43.

5. Fassil H. "We do what we know": Local health knowledge and home-based medicinal plant use in Ethiopia. Oxford University; 2003.

6. Shilema A, Zerom K, Ussa A. Ethnoveterinary practices against animal trypanosomiasis in amoro district, Southern Nations. Int J Med Rsearch. 2013;2:238-41.

7. N'Djetchi MK, llboudo H, Koffi M, Kaboré J, Kaboré JW, Kaba D, et al. The study of trypanosome species circulating in domestic animals in two human African trypanosomiasis foci of Côte d'Ivoire identifies pigs and cattle as potential reservoirs of Trypanosoma brucei gambiense. PLoS Negl Trop Dis. 2017;11:1-16.

8. Antoine-moussiaux N, Magez S, Desmecht D. Contributions of experimental mouse models to the understanding of African trypanosomiasis. Cell. 2008;24:411-8.

9. Committee for the Update of the Guide for the Care and Use of Laboratry Animals. Guide for the care and use of laboratory animals. 8th ed. Washington DC: The National Academies Press; 2011.

10. Ene A, Atawodi S, Ameh D, Nnamani C, Apeh Y. Antitrypanosomal effects of petroleum ether, chloroform and methanol extracts of Artemisia maciverae Linn. Indian J Exp Biol. 2009;47:981-6.

11. Herbert W, Lumsden W. T. brucei: A rapid matching method for estimating the host's parasitemia. Exp Parasitol. 1976;40:427-31.

12. Angela O, Mustapha L, David MY. Anti-trypanosoma activity of the ethanolic leaf extract of Senna occidentalis (Fabaceae) on T. brucei brucei infected mice. Int J Basic Appl Sci. 2013;2:32-7.

13. Maikai V. Antitrypanosomal activity of flavonoid extracted from $X$. americana stem bark. Int $\mathrm{J}$ Biol. 2011;1:115-21.

14. Ngulde S, Tijjani M, Ihopo J, Ya'uba M. Anti-trypanosomal potency of methanolic extract of Cassia arereh Delile root bark in albino rats. Int J Drug Res Tech. 2013;3:1-7.

15. Tasew S, Duguma R. Cattle anaemia and trypanosomiasis in Western Oromia State, Ethiopia. Rev Méd Vét. 2012;12:581-8.

16. Nweze N, Anene B, Asuzu I. Investigation of the anti-trypanosomal activity of Buchholzia coriacea seed extract against a field strain of $T$. congolense. Afr J Tradit Complement Altern Med. 2011;8:175-80.

17. Evans W. Trease and Evans' Pharmacognosy. 14th ed. W.B. Saunders Ltd; 1996.

18. Briggs M. Advances in steroid biochemistry and pharmacology. 4th ed. New York; 1970.

19. Rafauf R. Handbook of alkaloids and alkaloid containing plants. 2nd ed. New York: Wiley Academic Press; 2013. 
20. Sofowora A. Medicinal plants and traditional medicine in Africa. New York: John Wiley and Sons, Ltd; 1982.

21. Dermarderosian A, Liberti L. Natural products medicine: A scientific guide to foods, drugs and cosmetics. 1st ed. Philadelphia; 1988.

22. Tyler V, Brady L, Robbers J. Pharmacognosy. 9th ed. Philadelphia: Lea and Febiger; 1988.

23. Freigburghaus F, Kaminsky R, Nkuna M, Brun R. Evaluation of African medicinal for their in vitro tyrpanocidal activity. J Ethnopharmacol. 1996;55:1-11.

24. Wurochekke A, Nok A. In vitro and In vivo antitrypanosomal activity of the leaf of Lawsonia inermis against $T$. brucei brucei infection in mice. J Med Sci. 2004;4:236-9.

25. Stijlemans B, Vankrunkelsven A, Caljon G, Bockstal V, Guilliams M. The Central role of macrophages in trypanosomiasis-associated anemia: Rationale for therapeutical approaches. Endocrine, Metab Immune Disord - Drug Targets. 2010;10:71-82.

26. Hoet S, Opperdoes F, Quetin-leclercq J. Natural products active against African trypanosomes: a step towards new drugs. Nat Prod Rep. 2004;21:353-64.

27. Yabu Y, Yoshida A, Suzuki T, Nihei C, Kawai K. The efficacy of ascofuranone in a consecutive treatment on Trypanosoma brucei brucei in mice. Parasitol Int. 2003;52:155-64.

28. Toma A, Deyno S, Fikru A, Eyado A, Beale A. In vivo antiplasmodial and toxicological effect of crude ethanol extract of Echinops kebericho traditionally used in treatment of malaria in Ethiopia. Malar J. 2015;14:196.

\section{Figures}

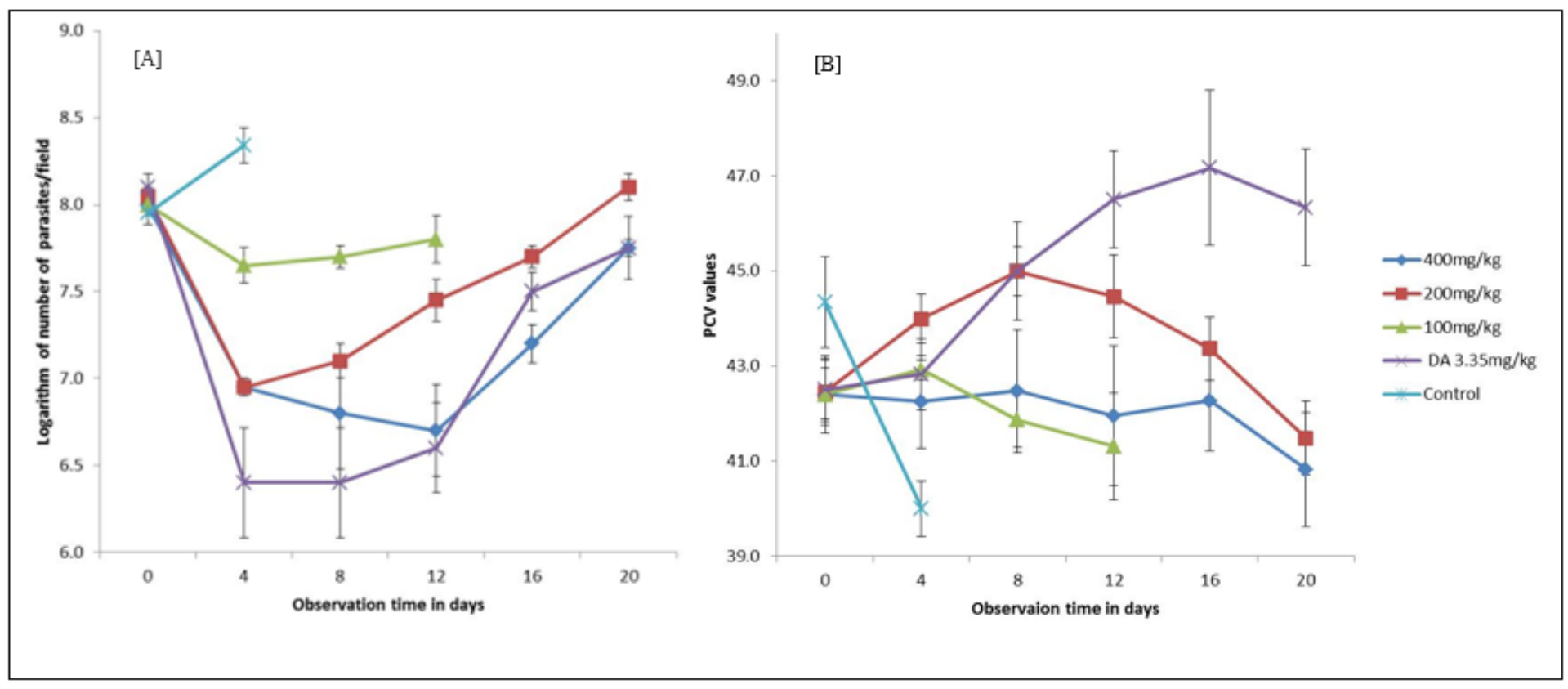


Figure 1

Effect of E. kebericho root extract. A) Effect on parasitemia parasitemia of T. congolense infected mice, B) Effect on PCV of T. congolense infected mice. Values are expressed as mean \pm SEM, Day $0=10$ th day after infected blood inoculation, DA= diminazene aceturate

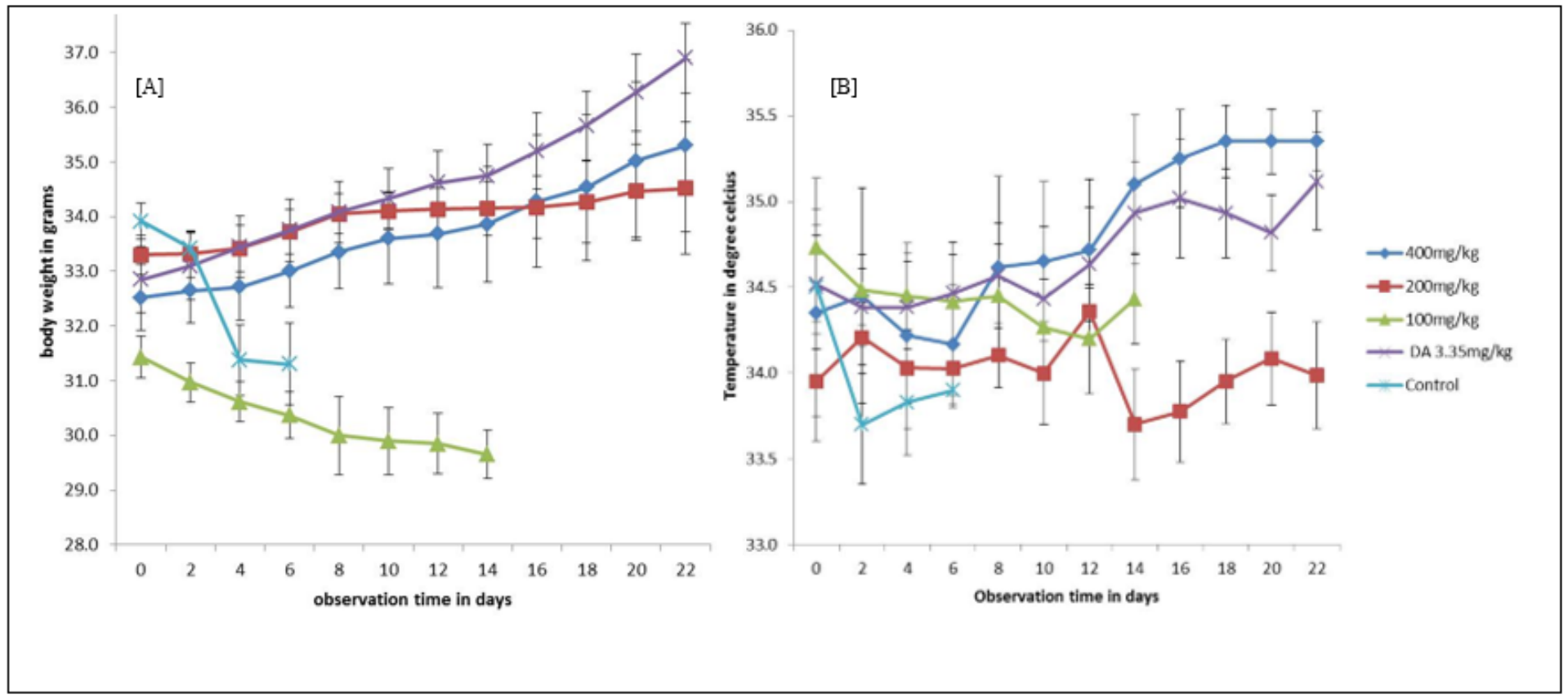

\section{Figure 2}

Effect of E. kebericho root extract. A) Effect on body weight of T. congolense infected mice, B) Effect on rectal temperature of $T$. congolense infected mice. Values are expressed as mean $\pm S E M, n=6$, Day $0=$ 10th day after infected blood inoculation, $\mathrm{DA}=$ diminazene aceturate

\section{Supplementary Files}

This is a list of supplementary files associated with this preprint. Click to download.

- NC3RsARRIVEGuidelinesChecklistfillable.pdf 